\title{
Macropolíticas do armário
}

\author{
A chave do armário. \\ Homossexualidade. Casamento. \\ Família.
}

ALMEIDA, Miguel Vale de.

Florianópolis: UFSC, 2010. 225 p.

- livro $A$ chave do armário. Homossexualidade. Casamento. Família, do antropólogo, ativista, professor da Universidade de Lisboa e ex-deputado português Miguel Vale de Almeida, é uma coletânea de textos apresentados em diversas conferências que derivam do projeto Práticas Familiares Contemporâneas em Portugal, financiado pela Fundação para a Ciência e Tecnologia e alojado no Centro de Estudos de Antropologia Social (atualmente parte integrante do Centro em Rede de Investigação em Antropologia Social - Cria), com trabalho de campo em Barcelona em 2005, onde foi realizada a pesquisa Family and Sexual Politics: The Challenge of Gay Marriage.

Miguel de Almeida inicia seu livro ponderando que os textos presentes em sua obra são o resultado de alguns anos da relação entre antropologia, pesquisas, intervenção pública e ativismo. A importância dessa ressalva está na afirmação de sua postura como acadêmico, político e militante de movimentos sociais, em especial o LGBT. De início, o autor sustenta uma descrença numa ciência pura que não se 
contamina pelo mundo social. A partir desse olhar, o antropólogo defende um ativismo, no complexo campo da política sexual, que esteja atento às análises e às críticas da ciência social, mas que ao mesmo tempo mantenha sua capacidade de agir. O terreno no qual Miguel se debruça é o das sociedades euro-americanas, em particular em Portugal, na Espanha, na França e nos Estados Unidos da América, e o seu foco são o casamento, a parentalidade e a família de pessoas homossexuais. Nesse sentido, a autor aponta que os reais objetos de suas pesquisas seriam a homofobia, a heteronormatividade, o sistema homofóbico e o armário:' a mais conhecida metáfora dos 'problemas' da homossexualidade (p. 14). Já na introdução de seu livro, o autor narra um pouco de sua história como ativista em grupos LGBT de Portugal e nos faz um breve percurso histórico desses movimentos em seu país.

Em "Orientação sexual e direitos humanos universais", primeiro capítulo de seu livro, Miguel faz uma revisão histórica do conceito moderno de cidadania e da invenção da figura do cidadão em contraposição a do súdito. Salienta pontos que foram definindo quem, como e por que alguém poderia ser considerado cidadão. Entre alguns elementos que atuaram na construção desse novo sujeito, Miguel cita o surgimento de aparelhos do Estado, a criação das economias nacionais e o colonialismo. O cidadão vai se tornando o sujeito que pertence a determinado Estado-Nação, que inclui o seu semelhante, mas que exclui o outro exótico, diferente. A partir dessa racionalidade, o antropólogo argumenta que o sexo, a raça e a cultura são linhas orientadoras para a definição de pertença e/ou de exclusão no e do EstadoNação ocidental. Ao discutir os direitos sexuais, - antropólogo segue em sua argumentação sobre como alguém se torna cidadão. Cidadania não seria mais somente possuir direitos políticos e, como acorre mais tarde, econômicos. Os movimentos sociais (como os gays e as feministas) e as políticas de identidade que surgem após a Segunda Guerra Mundial trazem para discussão pública a questão dos direitos humanos, de identidade, de cultura, e aqueles relacionados ao meio ambiente. Ao longo desse capítulo Miguel aponta as contradições inevitáveis no interior do movimento LGBT entre um essencialismo tático e a necessidade de romper com categorias de exclusão (hétero/homossexual). O capítulo se encerra com a defesa de que os direitos relativos à orientação sexual são o fim da linha dos conceitos modernos de cidadania e que ou são pensados como universais ou, caso contrário, não podem ser pensados.

No segundo capítulo, intitulado "'Até que a Lei vos uma': casamento, cidadania e ciências sociais nos EUA e na França", o antropólogo discute os estudos de parentesco e parentalidade entre as populações gays e lésbicas. Destaca as reflexões iniciadas nos anos 1960 que renovaram os estudos de parentesco no interior da antropologia a partir da crítica ao estruturalfuncionalismo. Dentre alguns marcos teóricos, o autor salienta a importância do feminismo, dos estudos de gênero, dos estudos gays e lésbicos e da teoria queer. A antropologia passa a ser confrontada por uma complexidade de formas conjugais e diversas pressões de movimentos sociais, o que a leva a rever etnocentrismos intrínsecos a alguns de seus postulados. Nesse contexto de rupturas teóricas, destacam-se teóricas como Gayle Rubin e Judith Butler. No decorrer desse capítulo, o autor destaca alguns contextos históricos, semelhanças, diferenças e dissonâncias entre Europa (especificamente o caso da França e a lei dos Pactos Civis de Solidariedade - PaCS) e EUA, no que diz respeito às políticas sexuais, casamento gay e uniões civis.

Em "The loving analogy: casamento interracial nos EUA e outras alianças proibidas", terceiro capítulo de seu livro, Miguel mostra como alguns movimentos que lutam pelo direito ao casamento entre pessoas do mesmo sexo (PMS) evocam, como precedente análogo, a proibição dos casamentos inter-raciais. O autor cita o caso Loving vs. Viriginia, de 1967, como sendo o casochave em relação às proibições de casamento entre pessoas de etnias diferentes, no qual um homem branco e uma mulher negra do estado de Virginia sofreram processos e condenações por se casarem. No âmago das discussões que envolviam antropologia e legislativo, pôde-se observar teorias racialistas, às quais se filiavam antropólogos, médicos, biólogos que defendiam concepções eugenistas. Contrariamente, outros especialistas, motivados por Franz Boas, passam a questionar e reagir contra as noções de raça e de determinismos biológicos. O casamento surge como problema no sentido de que sua efetivação possibilitaria, aos olhos dos racialistas, uma mistura genética impura e desnecessária. As leis antimiscigenação vigoraram nos EUA e tiveram forte influência na construção de um sistema judiciário marcado pela eugenia e pela supremacia branca. Os críticos às concepções racialistas propunham que a proibição à miscigenação, assim como as leis antissodomia 
e as leis que proíbem casamento entre PMS, por exemplo, atentam contra o direito constitucional à privacidade, previsto pela Equal Protection Clause.

No quarto capítulo, "Gentes remotas e estranhas: Espanha, 2005", Miguel discute as questões do casamento entre PMS e da políica sexual na Espanha a partir de um trabalho de campo realizado em Barcelona, em 2005. Ao analisar alguns pontos da legislação que alterou - Código Civil espanhol, o autor destaca, em relação ao casamento entre PMS, os aspectos igualitaristas e integracionistas, uma visão histórica e sociológica evolutiva e o reconhecimento das desigualdades históricas baseadas na orientação sexual. Para os movimentos espanhóis, o direito a se casar seria o teste supremo da homofobia: não aceitariam qualquer forma de união civil ou um tipo de casamento com outro nome. A frase "dignidade pressupõe igualdade" resumiria $\circ$ debate espanhol na luta pelo acesso à cidadania de pessoas LGBT. No entanto, havia também, na Espanha, posições contrárias ao casamento entre PMS vindas dos setores conservadores, que defendiam as uniões homossexuais sem estatuto e nome de casamento. Dentre os argumentos contrários estão aqueles também presentes em países como os EUA e a França: casamento é a união entre pessoas de sexo diferentes, casais do mesmo sexo ameaçam a proteção integral à criança, entre outros. Além das opiniões advindas da esfera pública laica, a Espanha também conta com uma forte tradição da Igreja Católica Apostólica Romana, que mantém uma visão normativa e dogmática em torno da sexualidade.

No quinto capítulo de seu livro, "Gentes próximas e familiares: relatos de Barcelona, 2005", Miguel apresenta o conteúdo de uma série de entrevistas realizadas em Barcelona, no ano de 2005, a fim de dar conta dos discursos dos atores e das atrizes envolvidos/as na discussão em torno do reconhecimento legal do casamento entre PMS. Segundo o autor, é possível identificar duas correntes que se encontraram possibilitando acesso ao casamento civil na Espanha: por um lado, as reivindicações do movimento LGBT e, por outro, o reconhecimento, por parte do partido no poder, da necessidade de integração europeia e de modernização da sociedade espanhola, que deveria corresponder ao processo liberal e democrático da igualdade de direitos, também no âmbito da orientação sexual. A questão da igualdade era central em ambas as correntes e fortemente defendida diante da constatação do que Miguel chama de realismo etnográfico: a existência de fato da homoconjugalidade e da homoparentalidade na Catalunha.

"Deste lado da fronteira: políica do gênero e da sexualidade no Portugal contemporâneo" é o nome do sexto capítulo do livro, em que o autor discute as condições de possibilidade não somente da aprovação do casamento entre PMS em Portugal, como também da própria formulação da questão "como é possível num país tão católico?". Miguel narra como a revolução que dera fim ao regime autoritário português e institucionalizou a democracia liberal fora importante para o desenvolvimento do país e sua adesão à Comunidade Europeia. No entanto, chama a atenção para o fato de a política sexual não ser pauta das agendas, as quais estavam mais focadas nas políticas de classe (a homossexualidade, por exemplo, só fora descriminalizada em 1982). Esse fato, segundo - autor, pode explicar a demora para o fortalecimento de movimentos sociais portugueses como os feministas e o LGBT, que irão se revitalizar apenas a partir da década de 1990. O autor aponta que o movimento LGBT em Portugal sofre de problemas comuns a outros movimentos sociais: pouca adesão de ativistas e voluntários; baixo incentivo público e privado; (in)visibilidade dos aderentes ao movimento; poucos estímulos das políicas antidiscriminatórias; baixa adesão às Marchas LGBT, que atingem números pouquíssimos expressivos (três mil participantes em média); e não inclusão das questões LGBT nas agendas dos partidos políticos.

No último capítulo, "Tempestade num copo de água: a antropologia e o casamento entre pessoas do mesmo sexo", ao discutir algumas transformações teóricas no interior da antropologia, Miguel aponta as perspectivas dessa disciplina no contexto contemporâneo, levando em consideração as sociedades ditas modernas e pós-modernas. Defende a ideia de que o casamento entre PMS "é uma conseqüência lógica da dinâmica das práticas do parentesco em sociedades e culturas como a nossa, decorrendo da aplicação [...] dos mesmos princípios aplicáveis ao casamento entre $s$ de sexo diferente" (p.199). Ao discutir teorias que postulavam os sistemas de alianças e trocas como a de Tylor e, principalmente, Lévi-Strauss, Miguel aponta um problema levantado hoje diante dessas teorizações: "quem troca quem?", "quem estabelece os termos de troca?". A inserção da teoria feminista na antropologia (com destaque aos trabalhos de Gayle Rubin) irá fornecer elementos para se problematizarem essas questões, fazendo operar uma revisão das noções 
de parentesco. Outras/os teóricas/os importantes nessas revisões seriam David Schneider e Marilyn Strathern. Porém, salienta Miguel (lembrando LéviStrauss): "não inventamos nada de radicalmente novo nem abolimos definitivamente estruturas anteriores" (p. 205). O casamento entre PMS seria, portanto, "a transformação da lógica do casamento apenas em termos da abrangência de novas categorias de indivíduos - neste caso definidos pelo sexo e pelo gênero" (p. 205). A relação de aliança/casamento continua sendo uma instituição central. Casamento existe no nosso momento histórico, e o reconhecimento ao seu acesso por PMS é uma questão política. Miguel encerra seu livro lembrando-nos de que a experiência social da homossexualidade desafia as heteronormatividades implícitas na antropologia, sobretudo no domínio do gênero, da sexualidade, da família e do parentesco. No entanto, esses desafios, se levados a sério, podem ser uma das chaves do armário.

$$
\star \star \star
$$

O livro de Miguel nos proporciona importantes reflexões no campo da política sexual, da cidadania e dos direitos humanos. Apesar de seus trabalhos se concentrarem nas realidades de países europeus e nos Estados Unidos, sua profundidade analítica antropológica e políica nos possibilita comparações, alargamento de discussões e um rico material argumentativo que pode respaldar as discussões sobre homossexualidades e gênero, tanto nos movimentos sociais LGBT como na produção acadêmica brasileira que se volta a essa temática. Seu pensamento reforça a necessidade e a importância da não dicotomização entre academia e política, trabalho intelectual e ativismo. O fazer acadêmico evidencia-se como eminentemente político, e Miguel nos atesta que essa forma de trabalho é possível.

Em suas análises encontramos muitas semelhanças com a realidade brasileira no que diz respeito às formas pelas quais as políticas sexuais e de gênero vêm sendo tratadas. No Brasil, a urgência reivindicatória dos movimentos LGBT se concentra na luta contra as formas de violência (les/homo/bi/transfobia) direcionada à população LGBT e tem como uma das maiores bandeiras a pressão para a aprovação do Projeto de Lei da Câmara n. 122/2006, lei que criminalizaria a homofobia. Já nos países analisados por
Miguel parece haver uma preocupação maior, por parte dos movimentos, em assegurar direitos civis iguais entre heterossexuais e homossexuais, em especial o acesso ao casamento, à possibilidade de constituição de família e à regularização das homoparentalidades. $O$ que nos salta aos olhos em ambas as realidades (Brasil e Europa/EUA) é a permanência de discursos e enunciados religiosos e pseudocientíficos no âmbito jurídico e político. Enquanto vemos alguns avanços em relação aos direitos da população homossexual, como o PaCS, na França e a legalização do casamento entre PMS em Portugal e na Espanha, no Brasil encontramos alguns impasses e entraves que impossibilitam uma maior discussão social sobre os direitos LGBT, bem como sobre a violência sofrida por essas pessoas.

Apesar de algumas conquistas brasileiras no ano de 2011, como a aprovação da união estável homoafetiva pelo Supremo Tribunal Federal, ainda vemos posições conservadoras e permeadas por ideais incongruentes a um Estado laico e democrático, como a recente suspensão do material educativo do "kit" Escola sem Homofobia. Algumas histórias e discursos parecem se repetir: o que se ouvia por lá e que, de certa forma, ao menos juridicamente fora superado, aqui ainda são sons bastante presentes. O livro de Miguel, nesse sentido, inspiranos teórica e politicamente, fazendo lembrar que as mudanças sociais, num mundo tão desigual e contraditório, são possíveis.

\section{Notas}

${ }^{1}$ Armário é um termo usado tanto popularmente como também fora incorporado aos movimentos LGBTTT e às teorias de gênero, de sexualidades e queer. Usualmente, é empregado para se referir a homossexuais não assumidos/as (dentro do armário) ou aos/às assumidos/ os (fora do armário). A expressão traz consigo questões de binarismos bem delimitados durante a modernidade: privado-público; segredo-revelação. O armário seria uma das figuras emblemáticas concernentes à questão da homossexualidade, a partir do final do século XIX, além de ser "[...] uma estrutura definidora da opressão gay no século XX" (Eve Kosofsky SEDGWICK, 2007, p. 26).

\section{Referências}

SEDGWICK, Eve Kosofsky. "A epistemologia do armário". Cadernos Pagu, v. 28, p. 19-54, jan./jun. 2007.

Daniel Kerry dos Santos Universidade Federal de Santa Catarina 